\title{
MECHANICAL AND MORPHOLOGICAL PROPERTIES OF TROPICAL WOOD POLYMER NANOCOMPOSITE
}

\author{
Md. Saiful Islam \\ Faculty of Engineering \\ Universiti Malaysia Sarawak, Sarawak, Malaysia \\ msaifuli2007@gmail.com
}

\begin{abstract}
This study looked into the manufacturing of wood polymer nanocomposites (WPNC) from several types of selected tropical wood species by means of phenol formaldehyde resin (PF) and hellysite nanoclay. The vacuum-pressure method was employed to impregnate wood samples with prepolymer mixture and in situ polymerization. The incorporation of Nanoclay inside wood was confirmed through FTIR and SEM respectively. The mechanical properties in terms of modulus of elasticity (MOE) and compressive modulus was found to be improved significantly on PF-Nanoclay treatment. Dynamic Young's modulus $\left(E_{d}\right)$ of wood was also calculated using free-free vibration testing. A significant increment was obtained for the PF-Nanoclay impregnated WPNC samples.
\end{abstract}

